\title{
De qué hablamos cuando hablamos de crónica contemporánea en América Latina
}

Resumen:

El campo de la crónica contemporánea en América Latina se encuentra hegemonizado por el llamado "Periodismo narrativo" que se propone narrar el presente sobre la base de investigaciones periodísticas. En un posicionamiento distinto y sin agruparse bajo ninguna denominación, una serie de escritores abocados a la crónica breve presentan un punto de convergencia en la filiación a la crónica modernista. La coexistencia de ambos posicionamientos provoca disputas en relación con las temáticas, los abordajes, los procedimientos narrativos y los posicionamientos autorales, en otras palabras, con la tradición cultural y literaria moderna. El binomio literatura/periodismo, nodal para el género, a partir de dichas pujas se ubica en el centro de la escena. Es por ello que, en el presente artículo, pretendemos iluminar la cuestión de la autodenominación, la obra literaria en juego y la concepción del lenguaje.

Palabras claves:

crónica, periodismo narrativo, literatura, periodismo

\section{Abstract:}

The field of contemporary chronicle in Latin America is hegemonized by the so-called "Narrative Journalism" that aims to narrate the present on the basis of previous journalistic investigations. In a different position and without grouping under any denomination, a series of writers dedicated to the short chronicle present a point of convergence in their affiliation to the modernist chronicle. The coexistence of both positions presents disputes in relation to themes, approaches, narrative procedures and author positions, in other words, with the modern cultural and literary tradition. The binomial literature / journalism, nodal for the genre, from these bids is located in the center of the scene. That is why, in this article, we intend to illuminate the issue of self-denomination, the conception of the literary work and language.

Keywords:

chronicle, narrative journalism, literature, journalism 


\section{Introducción}

La relación literatura/periodismo en el campo cultural latinoamericano de principios del siglo XXI se encuentra hegemonizada por la posición del denominado "Periodismo narrativo" (según la tradición latinoamericana de escritores nucleados en torno a la Fundación Gabo) o "Periodismo literario" (para la tradición crítica norteamericana y europea). Esta narrativa interesada en narrar la complejidad del presente de manera atrapante reclama el derecho a la no ficción que se garantizaría por las investigaciones periodísticas desde las que abordan los temas. El escritor norteamericano Mark Kramer, fundador del Programa Nieman de Periodismo Narrativo de la Universidad de Harvard, sostiene que se trata de un "tipo de texto en que las artes estilísticas y de construcción narrativa asociadas desde siempre con la literatura de ficción ayudan a atrapar la fugacidad de los acontecimientos, que es la esencia del periodismo" (2001: s/n). Esta vertiente de la crónica, cuyas denominaciones actualizan la de "Nuevo periodismo" acuñada por Tom Wolfe en los años sesenta, parten de la mezcla de técnicas literarias con temáticas referenciales. Desde otras latitudes, una de las principales escritoras y editoras argentinas de Periodismo Narrativo, Leila Guerriero brinda una definición similar a la de Mark Kramer: "... se llama periodismo narrativo a aquel que toma algunos recursos de la ficción estructuras, climas, tonos, descripciones, diálogos, escenas- para contar una historia real y que, con esos elementos, monta una arquitectura tan atractiva como la de una buena novela o un buen cuento" (2015: 32). Estas caracterizaciones vuelven evidente que en los cimientos de este posicionamiento se encuentra el núcleo ficción/ no ficción, problematizado hace tiempo, desde el campo de la crítica literaria, por Ana María Amar Sánchez en el clásico El relato de los hechos (1992). ${ }^{1}$ Más que retomar esta cuestión, interesa señalar que la consolidación del Periodismo Narrativo es actualmente un hecho ya que ha logrado crear una serie de instituciones que nuclean gran cantidad de escritores a través de cursos, talleres, festivales y premios. Referimos a la Fundación Gabo, ex Fundación para el Nuevo Periodismo Iberoamericano, en Colombia, la Fundación Tomas Eloy Martínez en Argentina y la Fundación Elena Poniatowska Amor en México. A su vez, tienen colecciones editoriales que se han ganado un espacio jerarquizado en las librerías y, en tal sentido, se hace evidente que cuentan con un mercado editorial y un público lector. Ello sin considerar las exitosas revistas especializadas de renombre internacional como Etiqueta negra, Anfibia, El Malpensante y Gatopardo.

Este tipo de crónica, que en las últimas décadas ha ganado adeptos sobre todo de jóvenes escritores que ansían ingresar al campo literario como adalides de los excluidos del sistema, ha despertado disputas por la definición tanto del campo literario como del periodístico y, en consecuencia, del campo de la crónica. Entre el sentido que incluye y el que excluye, es posible advertir un posicionamiento distinto en una serie de cronistas que sin agruparse bajo denominación alguna presentan un punto de convergencia en la afiliación a la tradición latinoamericana de la crónica modernista que supuso, entre otras cuestiones, la concepción del escritor como artesano de la prosa, la construcción de un nombre de autor en las páginas de la prensa periódica, la fragua del estilo al calor de la urgencia por la entrega y la maestría en el manejo de la brevedad. El quid del posicionamiento se encuentra en la confianza sin titubeos de los 
escritores en el valor de la intervención estética en medios periodísticos de circulación masiva.

Dos formas narrativas cobran entonces protagonismo y se disputan el campo de la crónica contemporánea en América Latina: la llamada "crónica de largo aliento", producto en mayor medida de escritores provenientes de academias periodísticas; y la crónica breve de los que referiremos como cronistas a secas, esto es, escritores autodidactas que se convirtieron en periodistas a golpes de oficio (no por haber estudiado Comunicación social o Periodismo). Una particularidad de estos últimos es que descreen de la división de tareas según la cual el Periodismo provee las historias y la Literatura, las herramientas para contarlas. Para aclarar tal distinción, recuperamos el planteo de Mónica Bernabé quien refiere a la crónica, concebida desde la academia literaria, como "la invención modernista de un dispositivo discursivo para exhibir lo nuevo hacia fines del siglo XIX (...) [donde] los modernistas fabularon sus imágenes de artistas en tensión con la información y abrieron un espacio para el ingreso de la literatura en el seno del periódico" (2015: 1); y a la crónica definida desde la academia periodística como el "resultado de un trabajo de investigación sin limitación temática, realizado en profundidad y apelando a estrategias y recursos propios de la narración de ficción" (Bernabé 2015: 1). Ambas narrativas agrupadas bajo el rótulo crónicas por el vínculo con la prensa presentan una serie de diferencias en cuanto a posicionamientos y estrategias que permitirán avanzar en algunas aristas de la relación literatura/periodismo que en este artículo indagamos.

\section{El autorreconocimiento en cuestión}

Los narradores identificados institucionalmente con la Fundación Gabo han asumido con gusto el bautismo "Nuevos cronistas de Indias" recibido en un foro de periodistas narrativos realizado en Bogotá en 2008. Alberto Salcedo Ramos, una de las voces más renombradas, cuenta que distintos medios de prensa advirtieron en aquel momento que "... a diferencia de los Cronistas de Indias originales, nosotros sabíamos darle voz a los excluidos" (2019: 12). Filiación genealógica a una tradición literaria de corte exotista que evidencia una particular motivación por aproximarse a territorios desconocidos para los lectores. ${ }^{2}$ A su vez, hay otros escritores que eligen nombrarse a sí mismos sencillamente como cronistas, esto es, cronistas a secas, ya que reivindican el hacer antes que una normativa o preceptiva. Esta línea minoritaria en términos numéricos que opera desde un accionar más individual que colectivo también ha materializado proyectos estéticos de relevancia literaria. A los fines del presente análisis, hemos decidido nombrar a estos escritores como cronistas sin más y a los Nuevos Cronistas de Indias como periodistas narrativos.

La mayoría de los escritores contemporáneos que producen y publican crónicas en América Latina, ya sea que se afilien a la tradición modernista de fines del siglo XIX o a la del Nuevo Periodismo del siglo XX, se definen como periodistas. Algunos - como hemos advertido - le agregan un adjetivo a dicha denominación al nombrarse como periodistas narrativos. Ahora bien, con el adjetivo o sin él, se vuelve patente que para escritores como María Moreno, Pedro Lemebel, Carlos Monsiváis, Juan Villoro y Jaime Bedoya, pertenecientes al grupo de los cronistas a secas, el periodismo refiere a una vocación asociada en el imaginario colectivo al campo 
popular en oposición a la aurática, glamorosa y aristocrática figura de escritor. En cambio, para Leila Guerriero, Cristian Alarcón, Alberto Salcedo Ramos, Julio Villanueva Chang y Juan Pablo Meneses (por nombrar representantes del Periodismo Narrativo de distintos países) supone una práctica codificada de investigación y reporteo como condición sine qua non para escribir. La identificación con el periodismo, que ambas vertientes manifiestan, connota en términos simbólicos referentes, saberes y tradiciones distintas que trataremos de esclarecer.

La autofiguración más común entre los periodistas narrativos (cuenta con un consenso casi unánime) es la de escritores investigadores, quienes a partir de la permanencia por un tiempo prolongado en el territorio elegido (desde la antropología se hablaría de trabajo de campo) ganaría en la aproximación al personaje o la situación en cuestión. Para esta narrativa que piensa sus métodos de un modo casi fundamentalista, el reporteo constituye una regla ineludible para que un relato pertenezca al género crónica. Ana María Amar Sánchez (2008 [1992]) plantea que el trabajo testimonial conlleva un procedimiento de subjetivación que inserta a los narradores y a los protagonistas en el relato provocando el predominio de los sujetos. Esa constante presencia de la voz del narrador en Cuando me muera quiero que me toquen cumbia (2003) de Cristian Alarcón (por dar un ejemplo representativo) permite advertir que el libro no cuenta la historia de la santificación de un "pibe chorro" (como se ha dicho en muchas ocasiones) sino que se trataría de la experiencia de un sujeto que se inserta en la villa para investigar las repercusiones de la muerte del "Frente Vital". La historia villera avanza conforme avanza el relato de la búsqueda de testimonios, anécdotas e información en general. En tal sentido, la construcción de un sujeto autoral fuerte, una primera persona presente en toda la relación con el objeto referido, constituye una marca del Periodismo Narrativo. Antonio López Hidalgo (2017) justifica el empleo de dicho recurso en el conocimiento que estos periodistas poseen del lector quien no sólo estaría ávido por conocer lo que le sucedió a los protagonistas sino también a los periodistas mientras investigaban. ${ }^{3}$ El periodismo constituiría entonces un saber hacer de carácter documental regido por la priorización de los denominados "hechos". Aspecto que amerita una aclaración: los periodistas narrativos conciben los hechos ante todo como cosas no porque se desconozca la hechura verbal de los mismos pero como si fuese posible anteponer la cosa a la interpretación de la cosa. Más allá de las críticas, resulta interesante traer a colación la reflexión del crítico español Albert Chillón quien, al refutar la concepción durkheimiana de los hechos que juzga representativa de la ideología periodística dominante, plantea: "los hechos son interpretaciones de cabo a rabo: tramas de sentido que se alimentan de lo evidente, lo comprobable, lo probable y lo pausible..." (2014: 125).

Si en el Periodismo Narrativo el tema investigado siempre se narra junto a las peripecias sufridas por el cronista, la construcción del narrador como un investigador resulta efectiva a los fines del pacto de lectura de no ficción que estos escritores sostienen como estandarte. Dicho pacto con el lector justificaría que estos libros sean editados, presentados y comercializados como crónicas y no como novelas. Una anécdota ilustrativa es la que cuenta Leila Guerriero sobre la búsqueda de un editor para Los suicidas del fin del mundo. En dicha ocasión, se le sugirió que lo escriba como si fuera una novela, propuesta rechazada - según sus propias declaraciones 
- porque hasta el agobio producido por el incesante viento patagónico debía ser leído como información, no como un "mero adorno" (Guerriero 2015: 59).4 Ciertamente es la inscripción del relato en el género crónica la que permite la connotación de veracidad con la que la escritora busca cargar cada elemento de la historia. Recuperamos el argumento aún con cierto reparo porque permitiría explicar la insistencia de los periodistas narrativos de aclararle al lector que lo que va a leer es una crónica.

Las autofiguraciones de los que denominamos cronistas a secas asumen otras características en principio porque se advierten sensibilidades fascinadas por la pluralidad de expresiones culturales, atentas a la diversidad de saberes pero sobre todo forjadas a partir de la postulación de formas de conocimiento alternativas a las que han primado en la tradición cultural latinoamericana. Referimos a la hegemonía del "saber leer" de la tradición literaria moderna centrada en el valor de la letra (y en el objeto libro) así como del "saber ver" característico de la tradición del género crónica evidente en la primacía de la figura del flâneur en el siglo XIX y del voyeur en el XX. En un gesto de diferenciación respecto de estos paradigmas, los cronistas a secas se retratan a sí mismos a partir de un "saber oír" o, en todo caso, de una escucha heterodoxa que les otorga mayor libertad en relación con la historia literaria y cultural. Buscamos señalar la primacía de escenas de escucha vinculadas a ámbitos culturales populares sobre escenas de lectura indefectiblemente asociadas a la Cultura con mayúscula. Esta cuestión que ponemos de relieve es fundamental porque, a pesar de que estos escritores son grandes lectores, sus autofiguraciones pivotean sobre la valorización de la palabra escuchada. En tal sentido, el acto de escuchar como instancia formativa (sea la radio, trasmisiones varias o lecciones políticas, por nombrar algunas opciones) constituye una práctica diferente del acto de leer. ${ }^{5}$

Asimismo, el interés por desmarcarse de las instituciones, sus reglas y normas aún con sus diferencias resulta una constante de los cronistas a secas, a quienes podríamos pensar como una suerte de comentadores, esto es, sujetos atentos a la cotidianidad que no pierden de vista el contexto histórico y cultural. Apelamos a la figura del comentador no porque ellos se denominen de dicha manera sino para proponer una imagen sin arraigo académico que represente esa pretensión de abordar los temas que podrían considerarse más banales con la misma profundidad con que tratan los temas socialmente valorados. Es importante destacar que estos escritores intervienen desde lo nimio y, por ello, sus crónicas constituyen notas, ideas, pensamientos u observaciones, que podrían concebirse como productos de un mitólogo en el sentido de Mitologías de Roland Barthes. El trabajo con asuntos aparentemente menores se reserva el derecho al fragmento y se desentienden de la incompletud. El cronista peruano Jaime Bedoya cimienta el trabajo de la crónica en el ejercicio de volver a mirar ahí donde parecería que ya está todo dicho como se puede deducir de la crónica "Frankenpollos": "La reflexión es pertinente a propósito del último feriado no laborable por duelo nacional en el que, sin embargo, sí trabajaron los Kentucky Fried Chicken. Este loable culto al trabajo demostrado por la transnacional del pollo frito amerita una mirada en detalle" (Bedoya 2004: 44). Esa mirada en detalle es la crónica misma. 
A partir de voces individualizadas en sus formas de contar, los cronistas a secas no intervienen desde el abordaje de temas prioritarios en términos sociales sino, al contrario, desde temáticas que hasta podrían resultar intrascendentes a las que precisamente apelan para interpelar el sentido común y las valoraciones culturales hegemónicas. Las nominaciones dadas por los propios cronistas a sus producciones permiten advertir que la asociación con lo menor encuentra valor estético en el enfrentamiento a la noción de obra. María Moreno refiere a sus crónicas como un "manojo de greguerías" (2001: 10) o, en una metáfora corporal, como "la saliva" (2002: 7). Expresiones asociadas a lo insignificante interpretadas por María José Sabo en relación con la tradición literaria moderna:

El grito, la saliva, el chirrido, la risotada; todas formas que Moreno emplea para referirse a su escritura en tanto justamente, formas que se vinculan a una cierta condición primigenia y espontánea de la expresión, y asimismo, a una condición rudimentaria, conforman posiciones de confrontación a la idea, y sobre todo, al mandato de la obra. (2015: 76)

Esos modos con que la escritora argentina define su escritura vuelven patente la lucha contra lo canónico, lo normado, lo establecido social y culturalmente, que buscamos esclarecer a nivel autofigural y que también se expresa en la escritura misma de los cronistas a secas.

\section{La obra en cuestión}

La asociación de la prosa periodística con una escritura de desecho junto con la caducidad del soporte (el periódico) aparecen como telón de fondo en la sostenida rivalidad entre la literatura y el periodismo que tuvo su inicio con la autonomización de los campos disciplinares a fines del siglo XIX. ${ }^{6}$ Esa rivalidad cobró particular relieve en la literatura latinoamericana desde el Modernismo y se sustentó en la valorización desigual de las prácticas de escritura a pesar de que, en muchos casos, fueron las mismas personas quienes ejercían ambas prácticas. Juan Villoro aborda jocosamente el tema a partir de imaginar las envidias que suelen suscitarse entre escritores y periodistas:

El fabulador "puro" suele envidiar las energías que el reportero absorbe de la realidad, la forma en que es reconocido por meseros y azafatas, incluso su chaleco de corresponsal de guerra (...). Por su parte, el curtido periodista suele admirar el lento calvario de los narradores, entre otras cosas porque nunca se sometería a él. Además, está el asunto del prestigio. Dueño del presente, el "líder de opinión" sabe que la posteridad, siempre dramática, preferirá al misántropo que perdió la salud y los nervios al servicio de sus voces interiores. (Villoro 2005: 9)

Juan Villoro, escritor por excelencia en las fronteras de los géneros, con la intención de desmitificar el enfrentamiento, contrasta estereotipos de escritor y periodista para demostrar que se trata de oficios distintos. Ni mejor ni peor. Las imágenes que cada uno crea del otro se forjarían sobre la falsa premisa de que el otro resuelve su trabajo sin mayores dificultades 
mientras que uno navega en aguas abiertas. La reflexión del escritor mexicano permite introducirnos en la cuestión de las jerarquías artísticas, el culto al libro y la concepción aristocrática de la palabra, elementos propios del imaginario moderno, que cobran relevancia en los posicionamientos de los cronistas contemporáneos.

Cuestiones vinculadas al prestigio literario se ponen en evidencia en el caso del Periodismo Narrativo en la necesidad de crear espacios de publicación dedicados en exclusiva al género. La aparición de revistas especializadas como Etiqueta negra, Anfibia, El Malpensante y Gatopardo cumplen el deseo de un lugar propio por y para la crónica al tiempo que se vuelven propicios para consolidar un nombre y una imagen de autor lejos de las connotaciones más prosaicas del oficio periodístico así como del nada glamoroso aspecto económico asociado a dicha práctica. El proceso de edición en ese tipo de publicaciones merece un comentario especial ya que requiere de un trabajo en equipo inusual para el escritor quien generalmente realiza un trabajo solitario. La particularidad radica en que el cronista y el editor comparten el largo proceso de escritura, situación que induce a pensar que mayoritariamente se trata de crónicas escritas, diremos metafóricamente, a cuatro manos. Guillermo Osorio, editor de Gatopardo, detalla los pasos:

Es un proceso muy largo y exhaustivo. Lo primero que tienes que hacer es conocer bien al autor. [...] En un autor nuevo y joven debes enterarte qué es lo que en verdad le interesa, tienes que conocer aquellas cosas que le despiertan curiosidad y todas sus manías y obsesiones. Y después tienes que sentarte a discutir con él la forma en que puedes convertir esos temas en crónicas o reportajes periodístico-literarios. Por ejemplo, el autor Emiliano Ruiz Parra. Él había reporteado sobre la Iglesia Católica en el periódico Reforma y aunque es ateo tiene un interés por la Iglesia como poder político. Eso me pareció interesante. Por eso empecé a hablar con él sobre las figuras que le interesaban. [...] Y entonces comenzamos a escribir perfiles sobre estos curas, perfiles de largo aliento con el objetivo de que posteriormente se pudiera hacer un libro que terminó escribiendo y que se llama Ovejas negras. (Benavides Bailón 2020: 144)

El editor asume un lugar importante al discutir los temas (cuando no los elige), supervisar el reporteo e intervenir la escritura en miras al mercado editorial (la referencia al número de ediciones es un dato en el que se insiste en la entrevista) así como a los reconocimientos institucionales (premios, distinciones o menciones). Esa búsqueda de talentos jóvenes a los que apadrinar es también el rol que cumple Leila Guerriero no sólo como editora de Gatopardo en el Cono Sur sino también para la colección "Vidas ajenas" de la editorial chilena Diego Portales. Intentamos señalar no solo el protagonismo que cobra la figura del editor sino el trabajo en conjunto con el cronista que deviene una constante del Periodismo Narrativo (podríamos decir que se trata de una regla implícita que el escritor debe aceptar). La situación se torna más evidente aún en la entrevista a Guillermo Osorio cuando le preguntan sobre su experiencia como editor de autores consagrados. Al respecto, relata una anécdota en la que Carlos Monsiváis se negó a que interviniera su escrito. ${ }^{7}$ Ello permite advertir que los cronistas a secas, a diferencia 
Cadernos de Literatura Comparada

De qué hablamos cuando hablamos de crónica contemporánea en America Latina

de los periodistas narrativos, establecen un límite preciso a la intervención del editor ya que entienden que el estilo surge de una batalla personal con el lenguaje que no están dispuestos a sacrificar.

El valor supremo del libro como materialización de la obra de un escritor aparece también de manera clara, para la tradición del Periodismo Narrativo, en la creación de colecciones específicas dentro de las editoriales. Por ejemplo, "Realidades" del sello mexicano Sexto Piso y "Ficciones reales" de la argentina Marea Editorial (dirigida por Cristian Alarcón) publican crónicas que en su mayoría no pasaron previamente por las páginas de diarios o revistas. Se trata de "crónicas de largo aliento" que, desde la perspectiva de una historia de la literatura, se aproximarían más a la novela que a la crónica como se la concibe desde el Modernismo en adelante. Más allá de esta apreciación genérica, no caben dudas de que la búsqueda de un espacio en las librerías responde a las ansias de autonomía respecto del periodismo aunque entendemos que la motivación pueda deberse a la extensión del trabajo.

A diferencia de este fenómeno de migración de las revistas al libro, los cronistas que escriben y continúan escribiendo a lo largo de sus vidas para distintos medios de prensa crean allí proyectos estéticos sin interés por disputar la pertenencia al ámbito de los escritores ni sus formas de legitimación. Pedro Lemebel ha sido claro al respecto: "Me interesa el desborde escritural más allá del libro, más allá de la biblioteca muda donde lo único que resuena es la palabra silencio escrita en un cartelito" (Alarcón 2002: 134). El escritor chileno es quizá quien más ha insistido en la preferencia por publicar en la prensa, elección que obedeció, en su caso, a la intención de ser escuchado por la mayor cantidad de gente posible y, a la vez, al deseo de escapar a la imposiciones del mercado editorial. ${ }^{8} \mathrm{El}$ desinterés del cronista por la cultura libresca se evidencia, a su vez, en el modo en que refiere a su obra como un "desborde escritural" operación con la que corre el foco del libro a la escritura. Por su parte, María Moreno ha señalado que el periodista Norberto Soares le trasmitió "una ética del escritor cuyo proyecto abjuraba del centro y de las seducciones del mercado" (2016: 138) jactándose de un posicionamiento desinteresado de las clásicas formas de consagración literaria. A propósito de ello, Carlos Monsiváis con gran sentido de la provocación expresa: “¿Quién hace periodismo si puede ser narrador?” (2010 [1980] 111) y, en la defensa de la escritura en la prensa, señala: “... la crónica mantiene la práctica de la literatura en un medio que prescinde de ella" (112). Así al tiempo que repone la desvalorización que el periodismo tenía en el imaginario social de los años setenta del siglo XX, manifiesta la conciencia (y la convicción) de intervenir a través de la literatura en un espacio hegemonizado por un discurso eminentemente informativo. Se trata de una motivación central de los cronistas: la intervención en el campo cultural (en nuestra tesis doctoral desarrollamos este aspecto en Carlos Monsiváis y María Moreno). Con estas reflexiones buscamos subrayar que, sin interés por reconocimientos institucionales, estos escritores han apostado por el valor de la intervención estética en la escritura cotidiana.

En definitiva, los cronistas a secas no persiguen una obra en el sentido clásico del término. La motivación para escribir no estaría en la publicación del libro, que para algunos de ellos deviene un mero producto, sino en el goce estético generado en el acto de escribir en sí mismo. 
Referimos a ese goce que se obtiene a partir del trabajo artesanal realizado con el lenguaje, la satisfacción proveniente de la conciencia de que se puede crear a través de las palabras. Claro que, a la vez, los cronistas escriben, podríamos decir, porque algo tienen que entregar a cambio del salario recibido. La escritura, en algún sentido, no deja de ser el tan trillado ganapán, una contraprestación en la que la exigencia de la entrega constituye la posibilidad de materializar el texto. En este sentido, la demanda del jefe de redacción lejos de obturar la escritura funciona para materializarla en palabras. La obra resultaría, entonces, eso que se va haciendo diariamente con la inspiración al palo y en el apuro de la entrega semanal.

\section{El lenguaje en cuestión}

Intento ser sincera, es decir miento con la verdad, aunque odio escribir en el simulacro de estar atrapando un instante verdadero.

María Moreno, Contramarcha.

Después de días, semanas o meses de trabajo, hay que organizar un material de dimensiones monstruosas y lograr con eso un texto con toda la información necesaria, que fluya, que entretenga, que sea eficaz, que tenga climas, silencios, datos duros, equilibrio de voces y opiniones...

Leila Guerriero, Zona de obras.

En el campo de la crónica al que venimos haciendo referencia, se aprecian tradiciones estilísticas distintas que pueden esclarecerse a partir de las afinidades, gustos y preferencias de los escritores. Es posible marcar, al menos en términos de tendencias (aun con el riesgo de la generalización), la predilección de los escritores pertenecientes a la corriente del Periodismo Narrativo por narradores norteamericanos y la inclinación de los cronistas a secas por escritores pertenecientes o próximos a la tradición barroca, esa que José Lezama Lima ha reivindicado como propiamente latinoamericana. Por esta razón, la escena de la crónica contemporánea se compone de escrituras que valoran las frases sencillas, cortas y directas en pos de un pragmatismo comunicacional, posicionamiento caracterizado por la primacía de la idea sobre la expresión, al tiempo que, de escrituras que apuestan por la búsqueda del significante más adecuado, que aprecian la riqueza adjetival de la lengua así como las frases que, en algunas ocasiones, han sido calificadas como enrevesadas.

La defensa del posicionamiento estético asumido en algunos periodistas narrativos llega a límites increíbles. En "Qué es y qué no es el periodismo literario: más allá del adjetivo perfecto", Leila Guerriero dictamina: "en el buen periodismo narrativo la prosa y la voz del autor no son una bandera inflamada por suaves vientos masturbatorios, sino una herramienta al servicio de 
la historia. Cada pausa, cada silencio, cada imagen, cada descripción, tiene un sentido que es, con mucho, opuesto al de un adorno" (2015: 36). La filiación a la tradición norteamericana de no ficción que la autora ha manifestado en más de una ocasión se muestra de manera clara en la ponderación de un estilo más bien austero y, como contracara, la condena a cualquier atisbo de barroquismo. El argumento principal que sostiene su posición es que los periodistas narrativos serían escritores cuya particularidad consiste en saber contar historias. Allí, interesa focalizar la reflexión: en la función comunicacional del lenguaje en la que éste se reduce a ser un medio para obtener un fin, a ser "una herramienta", en palabras de la escritora. Este posicionamiento, que conlleva la valoración de la trama en desmedro del trabajo con el lenguaje, se vuelve patente en frases como "un periodista narrativo es un gran arquitecto de la prosa, pero es, sobre todo, alguien que tiene algo para decir" (Guerriero 2015: 37). Fascinación por el tema (el qué, para los manuales de periodismo), en especial, si la temática se encuentra vinculada a algún tipo de violencia ejercida por el Estado o el poder económico.

La reflexión del crítico Martín Kohan sobre la diferencia entre los escritores que argumentan que cuentan historias y quienes sostienen que escriben textos resulta útil para identificar singularidades de cada uno de los posicionamientos:

No es lo mismo que se hable de "contar historias" o que se hable de "escribir textos". Y la diferencia no es menor, aunque pueda parecerlo; más allá de que los contadores de historias no pueden sino escribir, y más allá de que aquellos que apuestan a la escritura acaben por contar también historias de una manera u otra. Según el primer criterio, la escritura no va a ser otra cosa que una herramienta narrativa que tanto mejor cumplirá su función si se vuelve despejada y clara, si no se complica ni complica al lector, si fluye sin dificultades, si corre pareja y dócil. Quienes en cambio, anteponen la escritura, bajo la premisa de que en un texto literario la escritura es el objeto, mal podrían atenuar o subordinar aquello que en verdad es lo que más les importa. Percibir la escritura en un texto, demorarse en ella y paladearla, sería según este criterio lo más propio de la literatura. (Kohan 2018: 183)

La literatura parece homologarse, en una instancia, a una gran historia (sobra aclarar que, en nuestro caso, a quienes ubicamos allí es a los periodistas narrativos) y, en la otra, al acto intransitivo de escribir (en el que inscribimos a los cronistas a secas). Unos honran el objetivo temático y otros ponderan el nivel formal entendiendo que no hay forma sin contenido; unos, por precepto programático, se abocan a contar historias, a generar nuevos relatos; los otros, al anteponer la escritura, se destacan por la construcción de singulares prosas polifónicas que, como bien señala Kohan, también cuentan historias. Si recuperamos los epígrafes, advertiremos, como puede leerse en el planteo de Leila Guerriero, que los periodistas narrativos prefieren la eficacia comunicativa que garantiza la expresión más llana, más directa posible; mientras que, como se desprende de la reflexión de María Moreno, los cronistas coquetean con un pensamiento más bien paradojal, complejo, que no busca esconder el artificio que supone toda construcción discursiva. 
Hacia los años setenta, la experiencia del grupo Literal en Argentina resultó un manifiesto contundente refutando la capacidad instrumental del lenguaje. Aquellos "militantes del textualismo" (2020: 27), según lo nombrara Tamara Kamenszain, para quienes no había nada por fuera del lenguaje plantearon, enfrentados al discurso informativo, la necesidad de no matar la palabra. El posicionamiento apuntó contra la tiranía que todo referente ejerce sobre la lengua buscando que las palabras se liberen de las amarras que la llamada realidad les imponía. Una defensa de la polisemia, un acto de resistencia a la univocidad que todo motivo, asunto o historia busca implantar. La posición de los cronistas a secas, en especial, si consideramos su mirada crítica respecto del contenidismo, permite pensarlos como nuevos "militantes del textualismo" que lejos de la idea de la transparencia del lenguaje y desconfiados de la capacidad de los hechos para representar el mundo contemporáneo, reescriben -diremos para reforzar la idea de accionar sobre- la información. Pedro Lemebel plantea que si la crónica fundamentalmente lo que hace es registrar, lo que él hizo supuso un "re-narrar aquello que está registrado. Y en ese volver a narrar estaría la duda, duda que hace que ese mismo paisaje humano, social o cultural, lo pueda retratar de otra manera" (Ferreira 2018: 85). Una de las claves estilísticas de los cronistas a secas radica justamente en el juego que tiene lugar a nivel del significante, asociaciones propiciadas por los escritores como un modo de librarse de la referencialidad. En este sentido, estas escrituras no se encontrarían atadas a algo externo que deba ser representado, ni a un mensaje que deba darse, ni a mandatos morales, mucho menos a la agenda mediática. Cabe destacar, en dichos juego de significantes, la presencia de las referencias al imaginario de la cultura masiva manifiesta a través de películas, cómics, moda, series televisivas, temas musicales y figuras del espectáculo, entre otras.

\section{Conclusiones}

¿Qué hacemos con una sola palabra (crónica) para repartirla en prácticas tan diversas? El hecho de enfrentarnos como críticos literarios a la crónica contemporánea nos obliga, en una primera instancia, a deslindar, diferenciar, individualizar, el objeto. Y eso es lo que hicimos aquí principalmente. Este breve estudio sobre las principales vertientes de la crónica producida en América Latina en las últimas décadas al tiempo que, patentiza la riqueza y diversidad del género, evidencia la necesidad de reflexionar sobre las relaciones, cruces y negociaciones de los escritores en relación con el campo de la literatura así como con el del periodismo. La cuestión nominativa, abordada en el primer apartado, sirvió para probar que, a pesar de que desde una y otra vertiente los escritores se autofiguran como periodistas, dicha filiación presenta connotaciones bien distintas. Para los cronistas a secas, el periodismo simboliza la posibilidad de enfrentarse a la pomposa y rimbombante figura de escritor y, de ese modo, marcar la predilección por el campo cultural popular. Para los periodistas narrativos, además de una inscripción institucional, remite a una práctica específica de exploración y conocimiento de "lo real" indispensable para escribir. El tema de la obra, desarrollado en el segundo apartado, posibilitó invertir el foco para considerar la relación de los escritores con el campo literario. Corroboramos así que el Periodismo Narrativo adscribe a una idea más tradicional de literatura 
Cadernos de Literatura Comparada

De qué hablamos cuando hablamos de crónica contemporánea en America Latina

que tiene al libro (y, en especial, a la obra) como parámetro de consagración artística y, en ese sentido, es que procura habilitar para el periodismo un espacio específico en las librerías; mientras que los cronistas a secas buscan sostener un espacio para la literatura en la prensa diaria ya que vislumbran la posibilidad de que haya autores sin obra o, en todo caso, apuestan por espacios de escritura sin la intención de disputar la pertenencia al ámbito de los escritores. De este modo, han construido una literatura por fuera de los parámetros establecidos por la cultura letrada moderna. Por último, centrados en la cuestión del lenguaje, iluminamos que dichas prácticas de escritura se inscriben en tradiciones estéticas diferentes: los periodistas narrativos con una marcada propensión por la no ficción norteamericana presentan una concepción instrumentalista del lenguaje a partir de la que instituyeron la primacía del mensaje, la técnica del reporteo y la figura autoral del investigador; los cronistas a secas interesados en el hecho de escribir en sí o, en todo caso, desde una mirada que privilegia la escritura, se ocupan de la práctica escrituraria siguiendo cadencias, sonidos, demorándose gozosos en el texto.

\footnotetext{
NOTAS

* Julieta Viú Adagio es doctora en Humanidades y Artes con mención en Literatura por la Universidad Nacional de Rosario (UNR). Becaria posdoctoral del CONICET. Miembro del Instituto de Estudios Críticos en Humanidades (IECH-UNR) y de la Red Académica de Docencia e Investigación en Literatura Latinoamericana Katatay. Integra equipos de investigación en el área de literatura latinoamericana. Se desempeña como Auxiliar de Investigación en la Cátedra de Literatura Iberoamericana I de la Facultad de Humanidades y Artes (UNR). Ha publicado artículos en revistas nacionales e internacionales sobre la crónica latinoamericana que es su campo de especialización.
}

\footnotetext{
${ }^{1}$ Referimos a la crítica de Ana María Amar Sánchez al término "no-ficción": "El nombre de No-ficción dado por Capote al género se mantiene [en este trabajo] por razones de convención, ya que su uso se ha generalizado aunque sobre la denominación 'relato de no-ficción' pesa el implícito prejuicio de que todo relato 'normal' debe ser de ficción. De acuerdo con la hipótesis de este trabajo es más adecuado el de relato documental o testimonial" (2008 [1992] 11).

${ }^{2}$ Alicia Montes apunta respecto del exotismo que "en estos relatos, no se ofrecen al lector modelos perceptivos novedosos o inusuales que propongan la desnaturalización de los relatos dominantes o los discutan, por el contrario, muchos de ellos se contentan con una inversión de las interpretaciones hegemónicas, pero en una clave de lectura impregnada de cierta demagogia complaciente, para convertirlos en tipos exóticos consumibles..." (2014: 47, las cursivas son del original).

${ }^{3}$ Atendiendo a esta particularidad, se han publicado recientemente artículos que señalan como una marca distintiva del Periodismo Narrativo el relato de las emociones de los cronistas: Steven Bermúdez Antúnez (2017), Antonio López Hidalgo (2017) y Laura Ventura (2020).

4 La anécdota fue relatada por la escritora en "Tan fantástico como la ficción”, artículo originalmente leído en la Feria del Libro de Bogotá realizada en 2008, luego publicado ese mismo año en El Malpensante y finalmente antologado en Zona de obras.
} 


\begin{abstract}
${ }^{5}$ La hipótesis, desarrollada en trabajos anteriores (no se consignan en este versión del artículo para respetar el proceso de evaluación a doble ciego), sostiene que la autofiguración a partir de un "saber oír" antes que de un "saber leer" constituye una estrategia de los cronistas de identificación con ámbitos de la oralidad cultural.

${ }^{6}$ Una consecuencia secundaria pero no por ello menos importante producto de la fetichización del libro propia de la tradición literaria moderna fue, como ha señalado María José Sabo, que las escrituras periodísticas se han considerado "un resto indefectible del proceso de modernización" (2017: 111).

${ }^{7}$ Transcribimos a continuación el fragmento de la entrevista referido: "Jeovanny Moisés Benavides Bailón: Has trabajado con autores de la talla de Martín Caparrós, Carlos Monsiváis, Juan Villoro. ¿Cómo editar a este tipo de autores consagrados? ¿Cuál ha sido tu experiencia al trabajar con ellos? Guillermo Osorio: Imposible editarlos. Un día necesitaba editar un texto de Carlos Monsiváis, así que lo llamé por teléfono y le dije: -Mira, Carlos, voy a tener que hacerte algunas sugerencias sobre tu trabajo. Y él de la manera más elegante me respondió: -Edita mi texto hasta que lo reduzcas a una sola palabra. Me dejó entonces sin armas y lo dejé tal cual estaba" (2020: 145-146).

${ }^{8}$ Véase "La cultura mariposa", "La desnudez de la pobreza" y "Esa postura marginal", entrevistas antologadas en AA/VV. (2018), Lemebel oral. 20 años de entrevistas 1994-2004, Buenos Aires, Mansalva.

${ }^{9}$ Referimos al grupo de escritores nucleados en torno a Literal (1973-1977), revista argentina de culto, cuyos máximos exponentes fueron Germán García, Luis Gusmán y Osvaldo Lamborghini, autores que se singularizaron porque ejercieron y propiciaron el cruce entre literatura y psicoanálisis.
\end{abstract}

\title{
Bibliografia
}

AA/VV. (2018), Lemebel oral. 20 años de entrevistas 1994-2004, Buenos Aires, Mansalva.

Amar Sánchez, Ana María (2008), El relato de los hechos. Rodolfo Walsh: testimonio y escritura, Buenos Aires, Ediciones de la flor [1992].

Alarcón, Cristian (2003), Cuando me muera quiero que me toquen cumbia: vida de pibes chorros, Buenos Aires, Aguilar.

-- (2002), "El rey del colirio", Página/12, Radar, 10 de noviembre de 2002. <https://www. pagina12.com.ar/diario/suplementos/radar/9-473-2002-11-10.html> (Consultado por última vez el 1//2020)

Barthes, Roland (2002), Mitologías, Madrid, Editora Nacional.

Bedoya, Jaime (2004), Mal menor, Lima, Norma.

Benavides Bailón, Jeovanny Moisés (2020), "El cuidado por el estilo y la lucha por la prosa de calidad. Entrevista a Guillermo Osorno, ex editor de la revista de periodismo literario Gatopardo", Estudios de Teoría Literaria. Revista digital: artes, letras y humanidades, n. ${ }^{0} 20$, vol. 9. 142-147. <https://fh.mdp.edu.ar/revistas/index.php/etl/article/view/4434> 
Bermúdez Antúnez, Steven (2017): "La argumentación emocional en el periodismo narrativo", en Periodismo narrativo en América Latina, Antonio López Hidalgo (Coord.). Quito: Ediciones Ciespal.

Bernabé, Mónica (2015), "La hibridez no basta", Review. Revista de libros, no 5, 1-4.

Chillón, Albert (2014), La palabra facticia. Literatura, periodismo y comunicación, Valencia, Universitat de València.

Cristoff, María Sonia (2014), "La no ficción: una alternativa", en Falsa calma. Un recorrido por los pueblos fantasma de la Patagonia, Buenos Aires, Seix Barral, 9-21.

Ferreira, Carolina (2018), "Lírica errante de la crónica", en Lemebel oral. 20 años de entrevistas 1994-2004, Buenos Aires, Mansalva, 84-89.

Guerriero, Leila (2005), Los suicidas del fin del mundo. Crónica de un pueblo patagónico, Buenos Aires, Tusquets.

-- (2015), Zona de obras, Buenos Aires, Anagrama.

Kamensain, Tamara (2020), Libros chiquitos, Buenos Aires, Ampersand.

Kohan, Martín (2018), "Mapa tentativo de una contemporaneidad", en Historia crítica de la literatura argentina 12: una literatura en aflicción, Jorge Monteleone (Dir.), Buenos Aires, Emecé. 173-216.

Kramer, Mark (2001), "Reglas quebrantables para periodistas literarios", El Malpensante, n. ${ }^{\circ}$ 32, Bogotá.

Lezama Lima, José (1993), "La curiosidad barroca", en Sucesivas y coordenadas, Buenos Aires, Austral, 169-195.

López Hidalgo, Antonio (2017), "Otro nuevo periodismo es posible", en Periodismo narrativo en América Latina, Quito, Ediciones Ciespal, 9-16.

Monsiváis, Carlos (2010 [1980]), A ustedes les consta: antología de la crónica en México, Ciudad de México, Era.

Montes, Alicia (2014), Políticas y estéticas de representación de la experiencia urbana en la crónica contemporánea, Buenos Aires, Corregidor.

Moreno, María (2001), "Locuelas", A tontas y a locas, Buenos Aires, Sudamericana, 9-11.

-- (2002), "Preliminares", El fin del sexo y otras mentiras, Buenos Aires, Sudamericana, 7-10.

-- (2016), Black out, Buenos Aires, Random House.

-- (2020), Contramarcha, Buenos Aires, Ampersand.

Sabo, María José (2015), "Porque no habrá obra. El archivo en la escritura de María Moreno", Orbis Tertius, vol. XX, n. ${ }^{\circ}$ 22, 68-79. <https://www.orbistertius.unlp.edu.ar/article/view/ OTv2on22a07/7048> (Consultado por última vez el 11/01/2021)

- - (2017), "Una vuelta más a la cuestión "periodismo y literatura". El archivo, la crítica y los restos de la modernización latinoamericana”, Question, vol. 1, n. ${ }^{0}$ 53, 109-126. < https:// perio.unlp.edu.ar/ojs/index.php/question/article/download/3759/3209/> (Consultado por última vez el 12/12/2020)

Salcedo Ramos, Alberto (2019), De los viejos a los nuevos cronistas de Indias, Lima, Universidad Peruana de Ciencias Aplicadas. 
Ventura, Laura (2020), "La crónica latinoamericana actual: la empatía como elemento clave del género", Estudios de Teoría Literaria. Revista digital: artes, letras y humanidades, n ${ }^{0}$ 20, vol. 9, 106-113. <https://fh.mdp.edu.ar/revistas/index.php/etl/article/view/4464> (Consultado por última vez el 30/12/2020)

Villoro, Juan (2005), "Ornitorrincos. Notas sobre la crónica", en Safari accidental, Ciudad de México, Joaquín Mortiz, 9-19. 